\title{
DISCRETE MATERIAL AND THICKNESS OPTIMIZATION OF POP-UP SEAT FRAME IN STATIC CONDITION
}

\author{
Sang-In Moon
}

Graduate School of Mechanical Engineering, Kongju National University, 1223-24 Cheonan Dero, Cheonan-City, Chungnam, 31080, Republic of Korea

\section{Dong-Seok Shin}

Industrial Technology Research Institute, Kongju National University, 1223-24 Cheonan Dero, Cheonan-City, Chungnam, 31080, Republic of Korea

\section{Euy-Sik Jeon}

Department of Mechanical \& Automotive Engineering, Kongju National University, 1223-24 Cheonan Dero, Cheonan-City, Chungnam, 31080, Republic of Korea

\section{Seong-Min Cha}

Graduate School of Mechanical Engineering, Kongju National University, 1223-24 Cheonan Dero, Cheonan-City, Chungnam, 31080, Republic of Korea

\begin{abstract}
With the increase in the number of lightweight, high-strength and highperformance automotive parts, studies are being conducted on the application of highstrength and lightweight materials and the optimization of the thickness values of these parts. From a practical perspective, however, the indiscriminate use of highstrength and lightweight materials leads to very low mass production. Suggesting optimum design values also requires the adoption of new processes that are not practical for application in manufacturing processes. In this study, discrete material and thickness optimization (DMTO) that considers materials and thickness values for commercialization was applied.

A simple model of a retractable seat frame for recreational vehicles (RVs), whose thickness and material were not fixed, was investigated. Tests were conducted to secure accurate material properties for finite element analysis (FEA), and constraints were set based on the Federal Motor Vehicle Safety Standards (FMVSS) 207 and FMVSS 210 tests. The results of DMTO were compared with those of discrete thickness optimization (DTO) to verify the validity of the design parameters.
\end{abstract}

Keywords: Material, Thickness, FMVSS, DMTO, DTO. 
Cite this Article: Sang-In Moon, Dong-Seok Shin, Euy-Sik Jeon, Seong-Min Cha, Discrete Material and Thickness Optimization of Pop-up Seat Frame in Static Condition. International Journal of Mechanical Engineering and Technology 11(1), 2020, pp. 23-39.

https://iaeme.com/Home/issue/IJMET?Volume $=11 \&$ Issue $=1$

\section{INTRODUCTION}

The transport equipment manufacturing sector that largely contributes toward environmental pollution is attempting to reduce their contribution to environmental pollution through an improved fuel economy of vehicles. Studies have been conducted to reduce the weight of all automotive parts by changing their geometry, materials, and thicknesses [1-3]. Reducing the weight of parts is directly related to the safety of those seated in the vehicle, thereby lowering the safety performances of such parts. Ensuring both light weight and safety performance has long been a research topic of academia and industries [4-7].

A representative case of this problem is the seat frame, which occupies 3-5\% of the total weight of a vehicle and is most closely located to those seated. The seat frame must meet various safety standards and also consider weight reduction to improve fuel economy [8-10]. Previous studies on the lightweight seat frame have reduced the weight of specific parts by applying high-strength and lightweight materials or by adjusting their geometry and thicknesses [11-18]. It is almost impossible, however, that high-strength lightweight materials, such as carbon fiber reinforced plastic (CFRP) and advanced high strength steel (AHSS), are applied to all the parts. In addition, it is difficult to meet design parameters, such as thickness, accurate to the third decimal place.

In recent times, discrete optimum design methods that classify design parameters, such as materials and thickness, by identification (ID) have been further studied. Such methods divide materials and design specifications (thickness) using discrete IDs and apply such IDs to each part [19].

In particular, access to this problem has been frequently studied in the field of composite materials. Discrete material and thickness optimization (DMTO), which arranges materials and thicknesses in order of strength and optimizes them with discrete IDs, has been researched [20-22].

In this study, DMTO was applied to a simple seat frame model to determine its materials and thicknesses of its various parts.

The seat frame was discretized into a finite element model, and static and quasi-static test environments were subsequently applied. Design of experiments (DOE) and response surface methodology (RSM) were applied along with DMTO, and the parameters with low sensitivity were excluded from the optimization.

In addition, DMTO was applied to the finally selected main parts, and their optimization results were presented.

\section{PREFERENCE MODELING}

\subsection{Material Properties}

In this study, a relatively light glass fiber reinforced plastic (GFRP); SM 45C (carbon steel for machine structure use), a typical metal material; steel plate formability cold-rolled (SPFC) 980; and steel plate aluminized boron hot-rolled (SPBH) 1470 were selected as the study materials. The properties of each material can be obtained through the American Society for Testing and Materials (ASTM) D 638-02a and ASTM E8-E8M-15A standard tensile tests [23-25]. For the true strain-stress curve, the swift model was applied [26-32]. 


\subsection{Strain-Stress Curve}

Through the ASTM D 638-02a and ASTM E8-E8M-15A standard tensile tests, the actual material properties were presented in the stress-strain data.

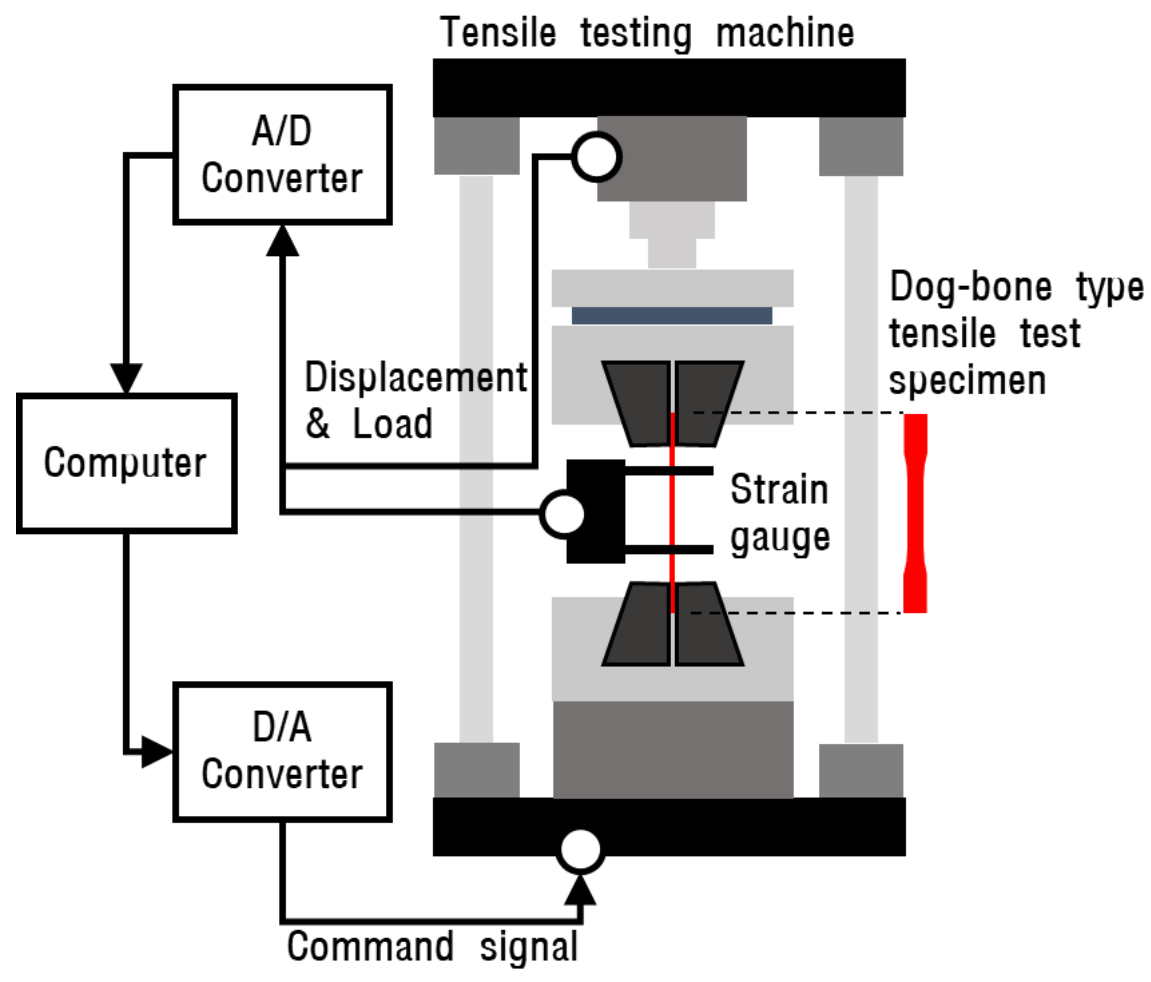

(a)
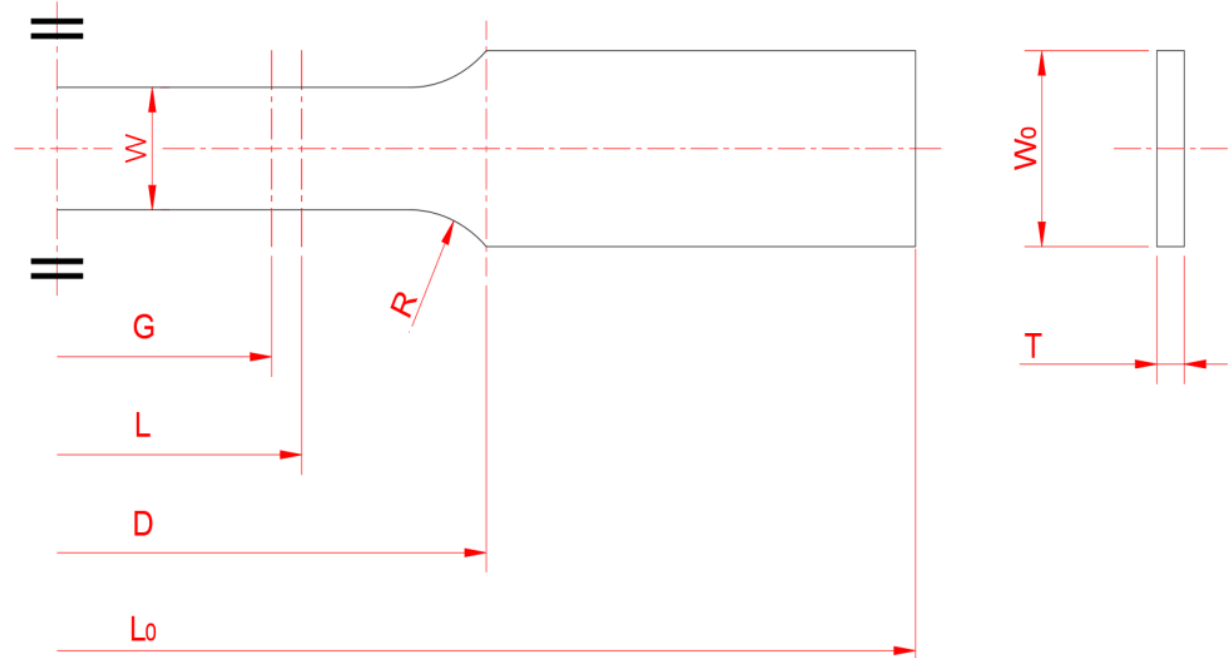

(b) 


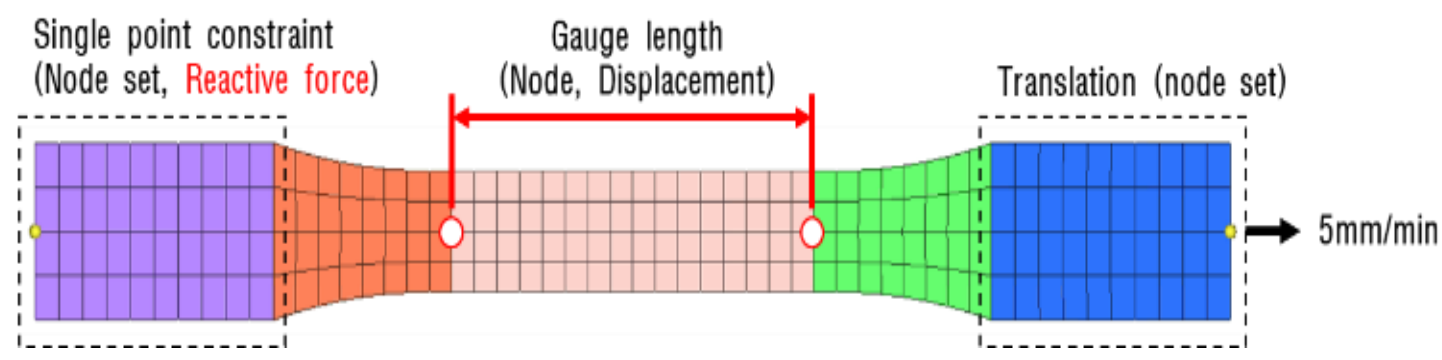

(c)

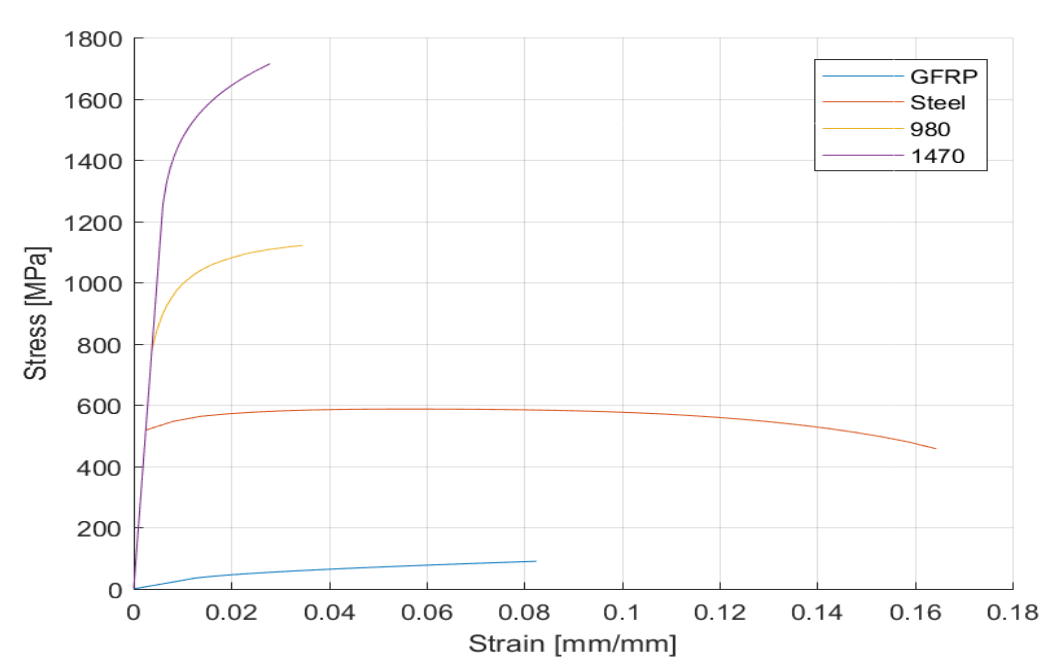

(d)

Figure 1 ASTM E8-E8M-15A test data (a) experimental setup, (b) dimensions of GFRP, SM 45C, SPFC 980, and SPBH 1470 specimens in accordance with ASTM standards, (c) test method for the SPBH 1470 specimen in accordance with the ASTM standard test method, and (d) experiment results of each property (nominal stress-strain curve)

Figure 1(a) shows the experimental setup for the standard tensile test in accordance with the ASTM standards. Based on the specifications presented by the standards, the specimens were fabricated as shown in Figure 1(b) and 1(c). Three or more tests were conducted to test each property, and the curve corresponding to the median value was selected as the representative property value. The representative values of each property obtained through the tests can be expressed as true stress-strain curves through the Swift equation [24-29]. The representative values of each property are shown in Figure 1(d).

Table 1 Mechanical properties

\begin{tabular}{cccccc}
\hline Symbols & Units & GFRP & Steel & SPFC 980 & SPBH 1470 \\
\hline $\mathrm{E}$ & $\mathrm{MPa}$ & 2756.09 & 210,000 & 210,000 & 210,000 \\
$v$ & - & 0.35 & 0.35 & 0.35 & 0.35 \\
$\sigma_{\mathrm{y}}$ & $\mathrm{MPa}$ & 27.43 & 518.15 & 766.96 & 1252.97 \\
$\varepsilon_{\mathrm{y}}$ & - & 0.01 & 0.0025 & 0.0037 & 0.006 \\
$\sigma_{U T S}$ & $\mathrm{MPa}$ & 89.88 & 586.95 & 1120.88 & 1714.40 \\
\hline
\end{tabular}




\subsection{CAD Modeling of the Retractable Seat Frame}

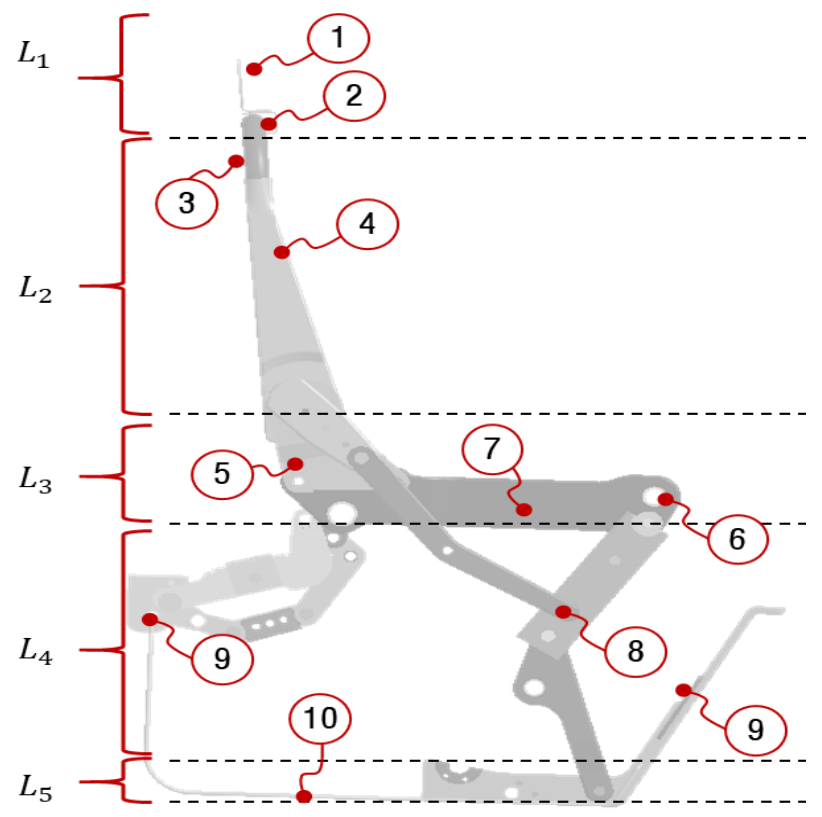

(a)

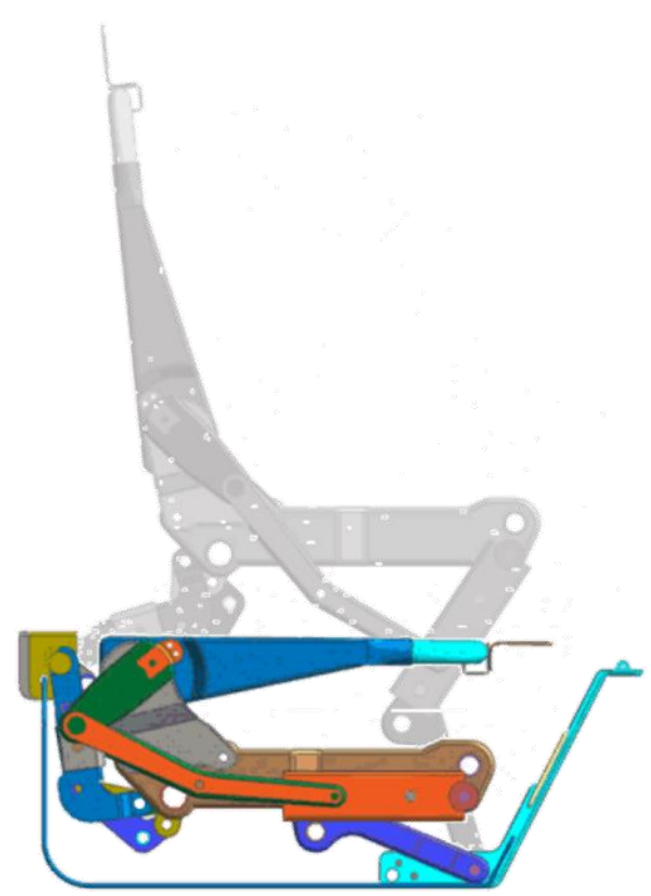

(b)

Figure 2 Parts of the retractable seat (a) conceptual model of the retractable seat applied to the rear row of RVs (b) retractable function using convenience parts

For the retractable seat, a conceptual design model applied to the rear row of recreational vehicles (RVs) was selected [33]. Figure 2 and Table 2 present information on the parts. Figure 2(a) depicts the conceptual design model. The model shows that the retractable seat moves up and down and several link parts are applied for spatial movement. In general, the retractable mechanism applied to the rear row of RVs is used for variably changing the storage and passenger spaces. 
Table 2 Descriptions of the assembled seat parts

\begin{tabular}{|c|c|c|c|}
\hline Layer & Symbol & Category & Description \\
\hline \multirow{2}{*}{$\begin{array}{c}L_{1} \\
\text { (Head-Restraint) }\end{array}$} & 1 & 100 & Headrest frame \\
\hline & 2 & 200 & Pole arm \\
\hline \multirow{2}{*}{ (Seat back) $^{L_{2}}$} & 3 & 200 & Main frame of seatback \\
\hline & 4 & 200 & Side frame of seatback \\
\hline \multirow{3}{*}{$\begin{array}{r}L_{3} \\
\text { (Seat cushion) }\end{array}$} & 5 & 300 & Bracket of cushion \\
\hline & 6 & 300 & Main frame of seatback \\
\hline & 7 & 300 & Side frame of seatback \\
\hline \multirow{2}{*}{$\begin{array}{c}L_{4} \\
\text { (Rail, Convenience parts) }\end{array}$} & 8 & 400 & Linked parts for convenience \\
\hline & 9 & 400 & Fixed parts \\
\hline (Base) & 10 & 100 & Base \\
\hline
\end{tabular}

\subsection{Finite Element Modeling}

All parts of the seat frame were constructed as two-dimensional finite elements. The average length of the elements was $5 \mathrm{~mm}$, and they met the basic element quality standards provided by HyperMesh [34-35]. Fastener products, non-contact seat belts, and joints were constructed as one-dimensional elements. The Federal Motor Vehicle Safety Standards (FMVSS) 207 rear moment test and the FMVSS 210 anchorage test (side moment test) were applied to verify the safety standards of the seat frame. Figure 3 shows the conceptual diagram of the seat frame to which the FMVSS 207 and FMVSS 210 test specifications apply [36-39].

In the basic analysis phase, the thicknesses and materials were unified. One material among GFRP, SM 45C, SPFC 980, and SPBH 1470 was applied to all parts in the same manner. In addition, thicknesses of $0.5 \mathrm{t}, 1.0 \mathrm{t}, 1.5 \mathrm{t}$, and $2.0 \mathrm{t}$ were applied to all parts in the same manner [40].

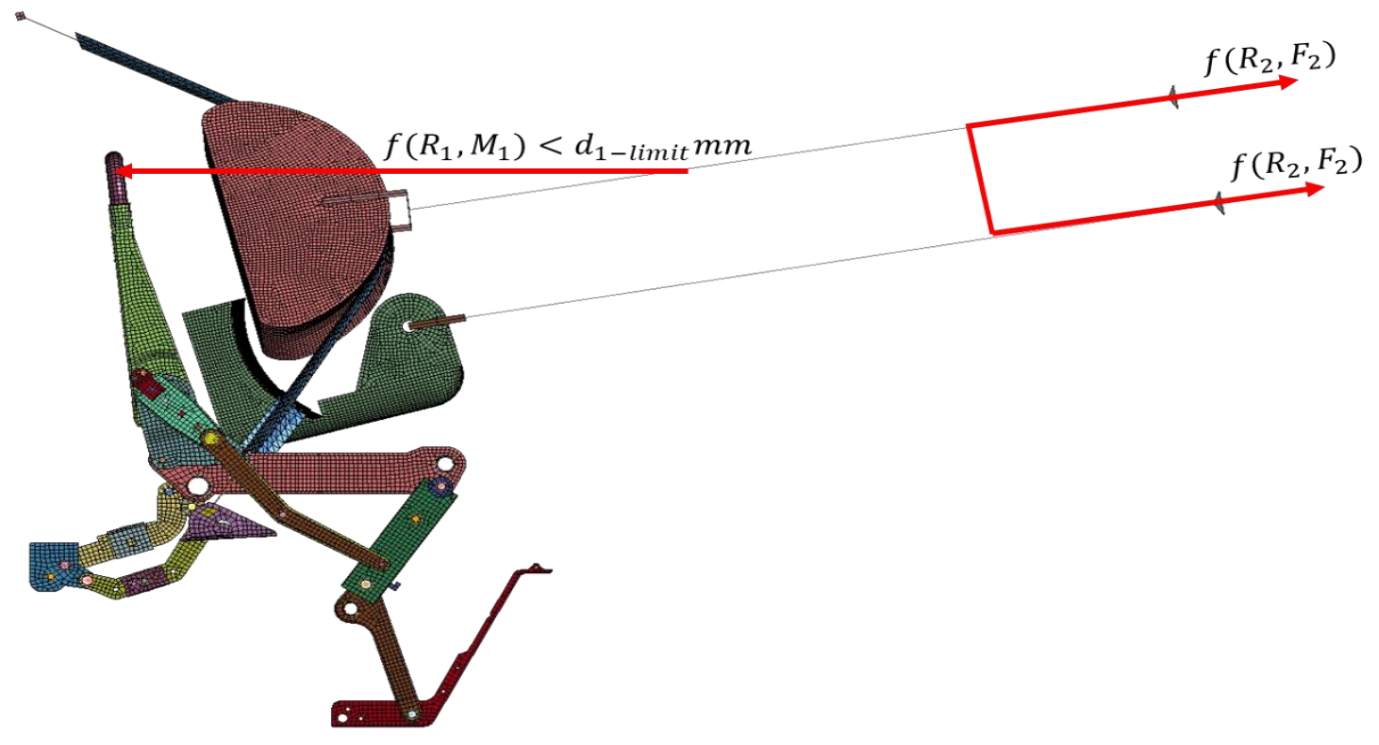

Figure 3 Finite element model subjected to FMVSS 207 and FMVSS 210 test specifications 
Discrete Material and Thickness Optimization of Pop-up Seat Frame in Static Condition

Table 3 Overview of the test environments applied to the retractable seat

\begin{tabular}{cccccc}
\hline $\begin{array}{c}\text { Initial } \\
\text { Number }\end{array}$ & Regulation & $\begin{array}{c}\text { Symbol } \\
{[\boldsymbol{R}]}\end{array}$ & $\begin{array}{c}\text { Analysis } \\
\text { type }\end{array}$ & $\begin{array}{c}\text { Input } \\
{[\boldsymbol{M} \text { or } \boldsymbol{F}]}\end{array}$ & $\begin{array}{c}\text { Limits } \\
{[\boldsymbol{d}]}\end{array}$ \\
\hline 1 & FMVSS 207 & $R_{1}$ & Static & $784[\mathrm{Nm}]$ & $80[\mathrm{~mm}]$ \\
\hline 2 & FMVSS 210 & $R_{2}$ & Quasi-static & $13[\mathrm{kN}]$ & $-[\mathrm{mm}]$ \\
\hline
\end{tabular}

\section{FINITE ELEMENT ANALYSIS (FEA)}

\subsection{FMVSS 207/210 Analysis Results}

The transport equipment manufacturing sector that largely contributes toward environmental pollution is attempting to reduce their contribution to environmental pollution through an improved fuel economy of vehicles. Studies have been conducted to reduce the weight of all automotive parts by changing their geometry, materials, and thicknesses [1-3]. Reducing the weight of parts is directly related to the safety of those seated in the vehicle, thereby lowering the safety performances of such parts. Ensuring both light weight and safety performance has long been a research topic of academia and industries [4-7].

For the FEA, LS-Dyna's explicit solver was used, along with a total of $16 \mathrm{CPU}$ cores. For memory, 800,000 WORD was used. Figure 4 shows the results of the FEA to which the FMVSS specifications were applied.

Figure 4(a) shows the displacements for the FMVSS 207 test environment. The analysis results show that the frame composed of GFRP could not meet the FMVSS 207 standard regardless of the thickness. The frames composed of metals, however, met the FMVSS 207 standard under the $1.0 t$ condition.

Figure 4(b) shows the results of the FEA for the FMVSS 210 test environment. The frame composed of GFRP could not meet the standard. The frames composed of metals could also not meet the test standard under the $0.5 \mathrm{t}$ and $1.0 \mathrm{t}$ conditions.

Figure 4(c) shows that the GFRP 2.0t model is lighter than the SPBH $14700.5 \mathrm{t}$ model. For parts relatively less affected by load, the weight reduction effect can be improved by incorporating plastic materials.

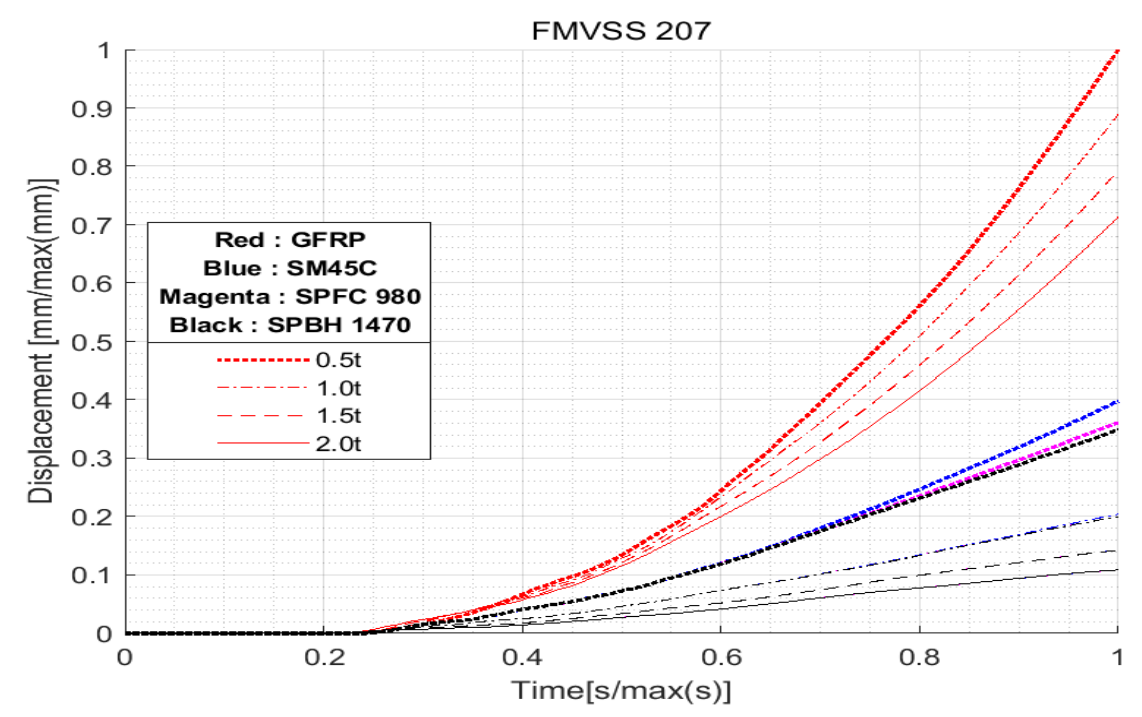

(a) 


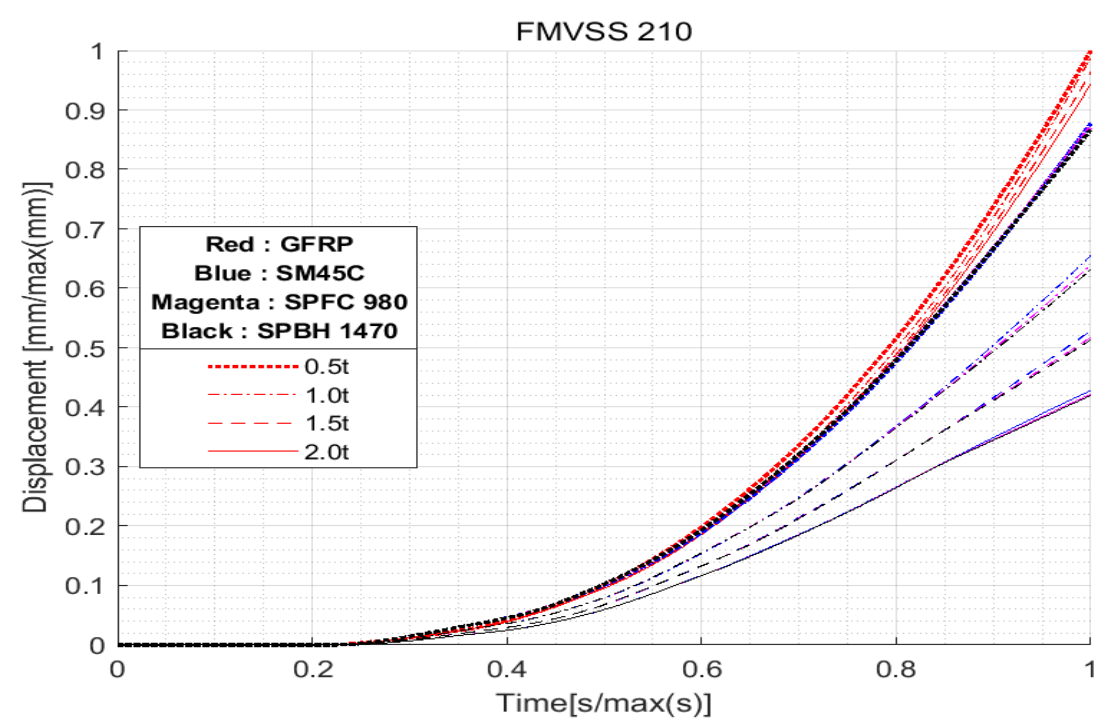

(b)

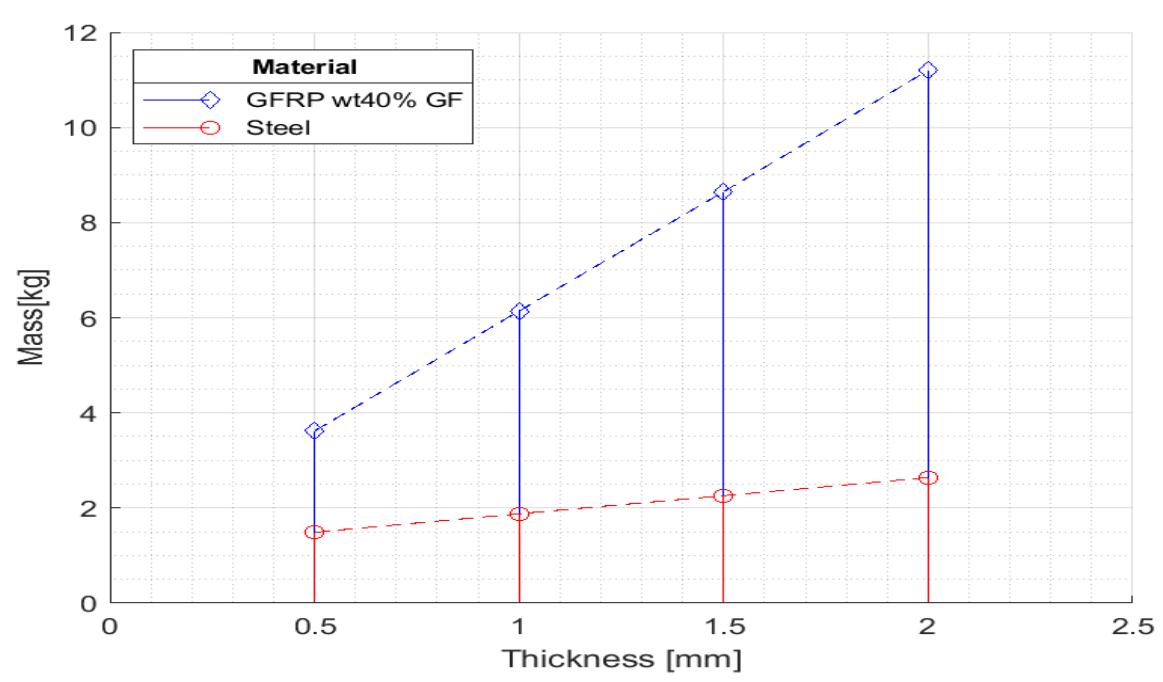

(c)

Figure 4 Strength of the finite element model according to the thickness (a) FEA results for a general seat (b) FEA results for the retractable seat (c) Frame mass according to the material and thickness

\subsection{Discrete Thickness Optimization}

General seat frame optimization studies have suggested methods for deriving the appropriate thicknesses and geometry while the materials of parts are unified. As there are 29 target parts, there are also 29 thickness parameters to consider. If each parameter involves four levels $(0.5 \mathrm{t}, 1.0 \mathrm{t}, 1.5 \mathrm{t}$, and $2.0 \mathrm{t})$, more than 100 case studies must be conducted. Therefore, in this study, D-Optimal DOE was used to efficiently reduce the number of conducting FEA [41]. The FEA result (displacement) was analyzed to generate a meta-model using the polynomial method. Figure 5(a) shows this optimization process. The optimal point of the meta-model was determined using G.A., and the effects of each parameter on the strength and weight are shown in Figure 5(b). Via the meta-model analysis, two seatback parts, two seat cushion parts, and four link parts were derived as parts that have more than $4 \%$ of the influence on strength and weight. Figure 5(c) shows the selected parts. 
Discrete Material and Thickness Optimization of Pop-up Seat Frame in Static Condition

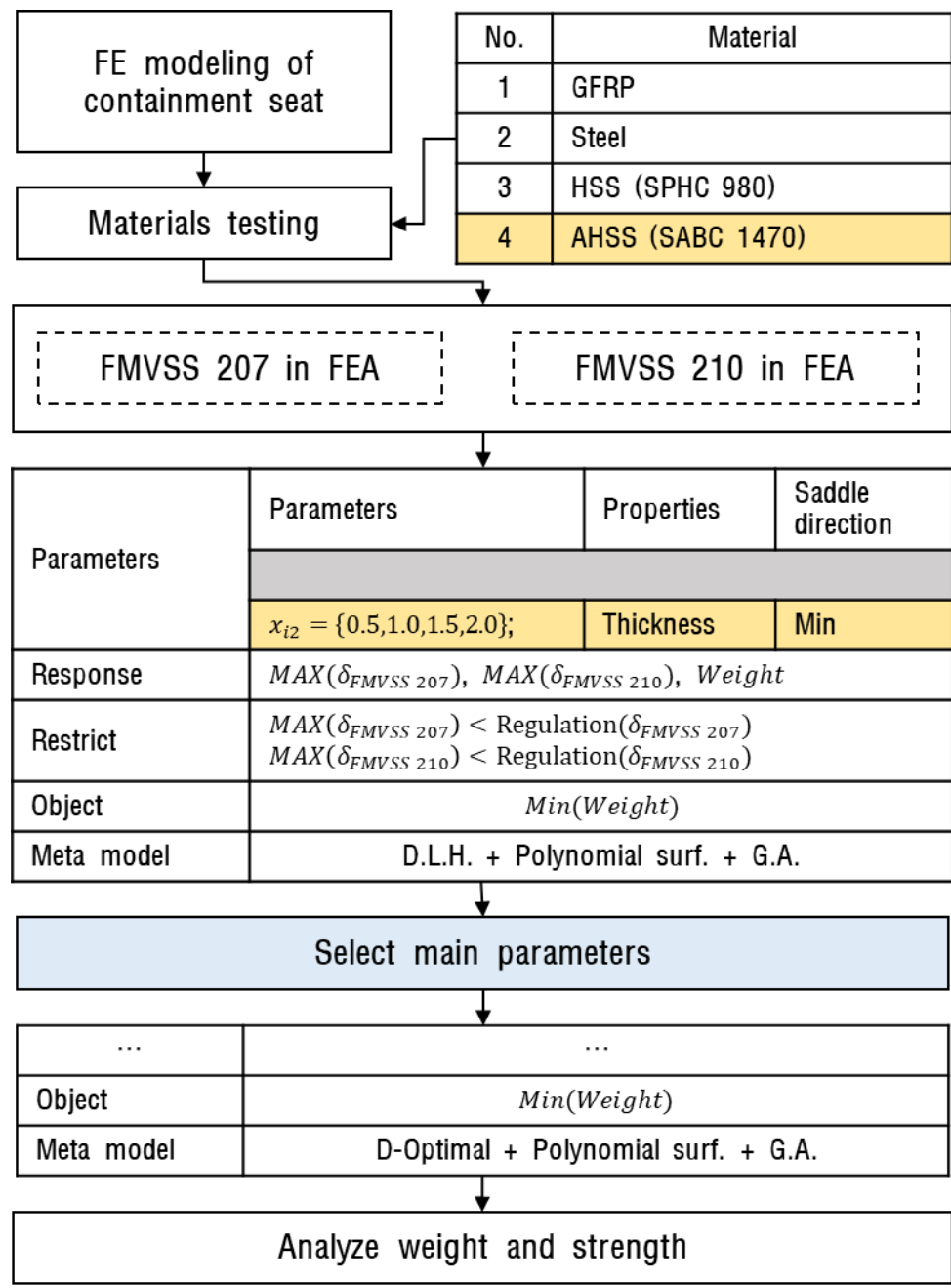

(a)

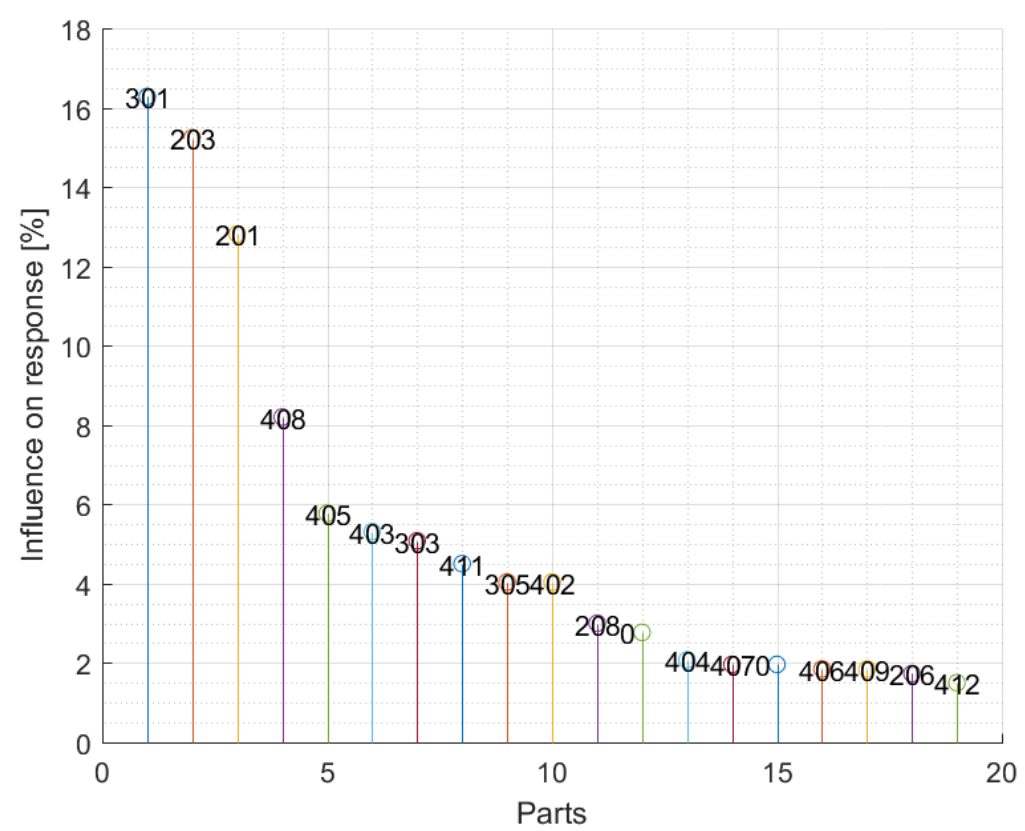

(b) 


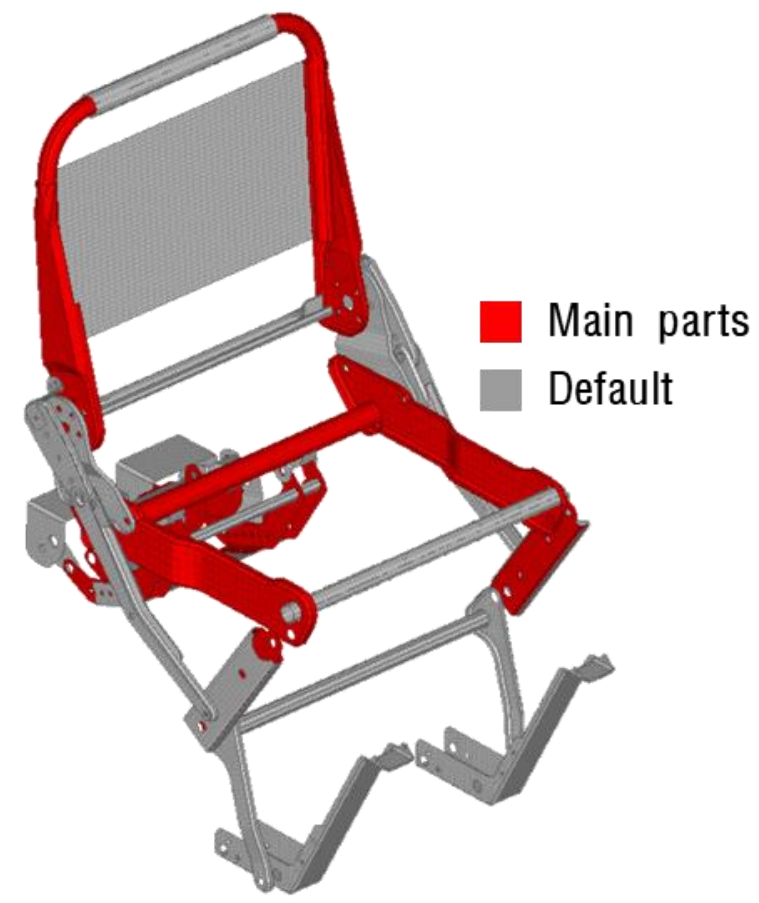

(c)

Figure 5 Results of detecting weight reduction levels using strength problems employing the thickness parameter (a) Diagram of discrete thickness optimization (b) Tthe result of global sensitivity (c) Parts that have a major impact on strength and weight

The default parts presented in Figure 5(c) were of 1.0t and were excluded from repeated DOE. Figure 6 shows the results of performing optimization using only the major parameters. The major parameters were optimized using the meta-model through DOE. In this process, errors of the meta-model may occur as shown in Figure 6(a). In this case, the ranges of the parameters were reduced based on the optimal point to generate a precise meta-model. When the errors of the meta-model reduced to below 3\%, the optimization process was terminated. The FMVSS test standards were met in all thickness optimization processes. The discrete thickness optimization (DTO) results with SPHB 1470 exhibited a weight reduction effect of approximately $42 \%$, as shown in Figure 6(b).

Figure 6(b) shows very satisfactory weight reduction results theoretically. It is very difficult, however, to actually apply SPHB 1470 to all parts in terms of mass production and cost. Therefore, high-strength and lightweight materials need to be incorporated only to parts that require them even though the weight reduction effect decreases. 


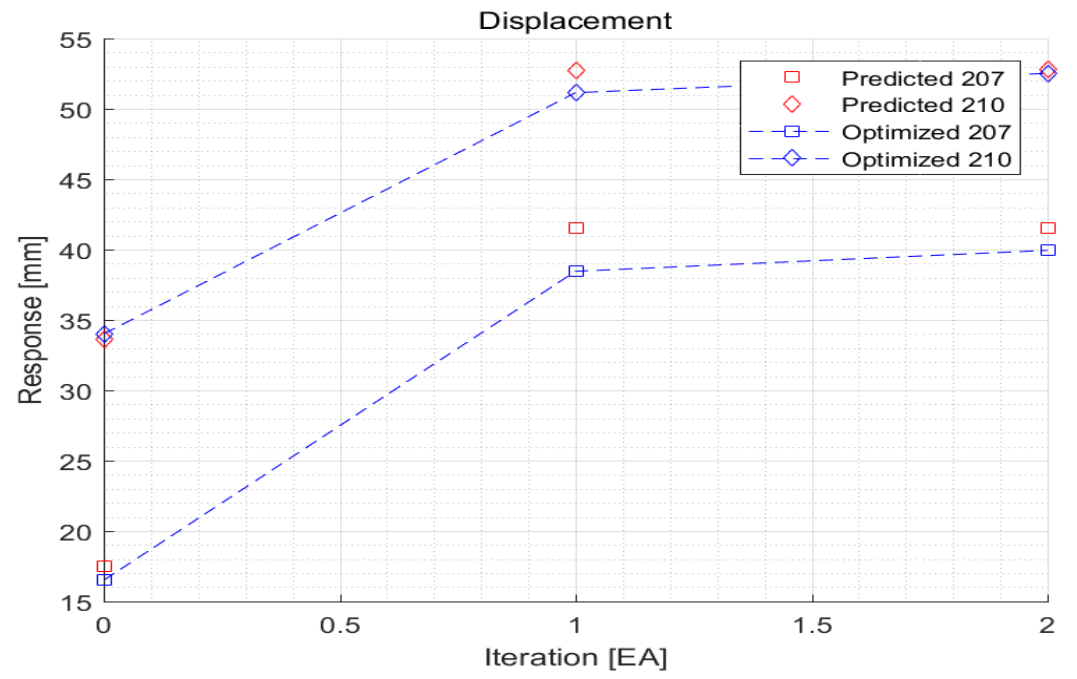

(a)

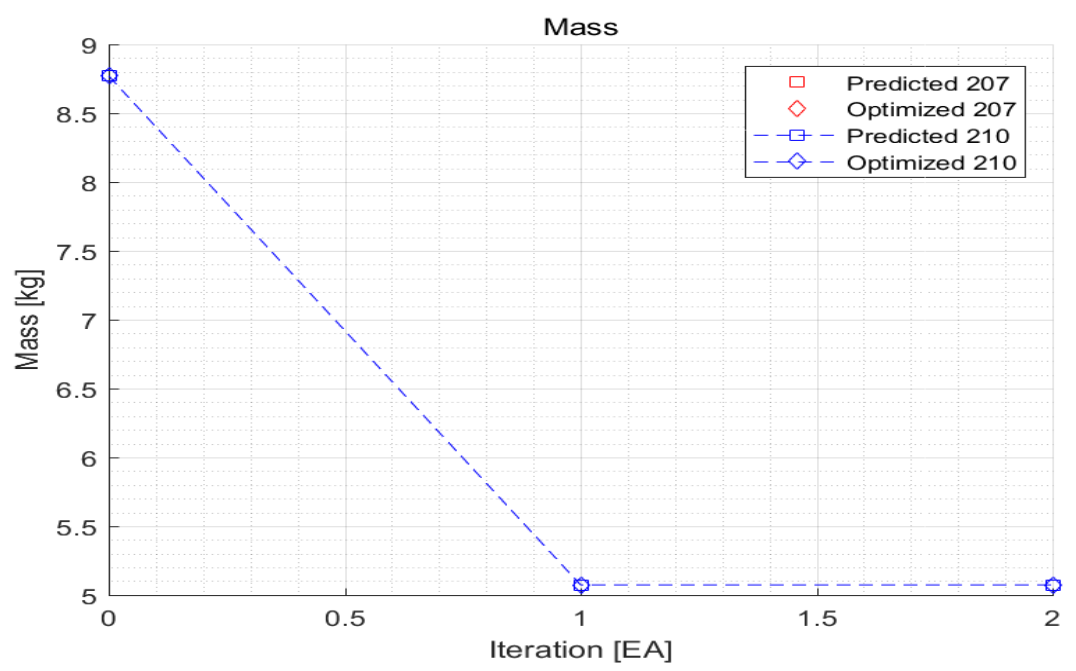

(b)

Figure 6 Result of discrete thickness optimization (a) Maximum displacement prediction of the optimization model and analysis results (b) The results of discrete thickness optimization

\section{DISCRETE MATERIAL AND THICKNESS OPTIMIZATION}

\subsection{Major Parameters of DMTO and DOE Setting}

Due the optimization procedure of DMTO, four material ID values were added for each part. The IDs of GFRP, steel, SPFC 980, and SPBH 1470 were set to 1, 2, 3, and 4, respectively. The thickness was classified into $0.5 \mathrm{t}, 1.0 \mathrm{t} 1.5 \mathrm{t}$, and $2.0 \mathrm{t}$. As such, there was no procedural difference from DTO.

As the process of deriving the main parts is the same as that discussed earlier, the main part numbers derived from DTO were used as they were. For parts that had less than $1 \%$ of the influence on strength and weight, low-strength and lightweight materials, such as GFRP, were applied. 
Sang-In Moon, Dong-Seok Shin, Euy-Sik Jeon, Seong-Min Cha

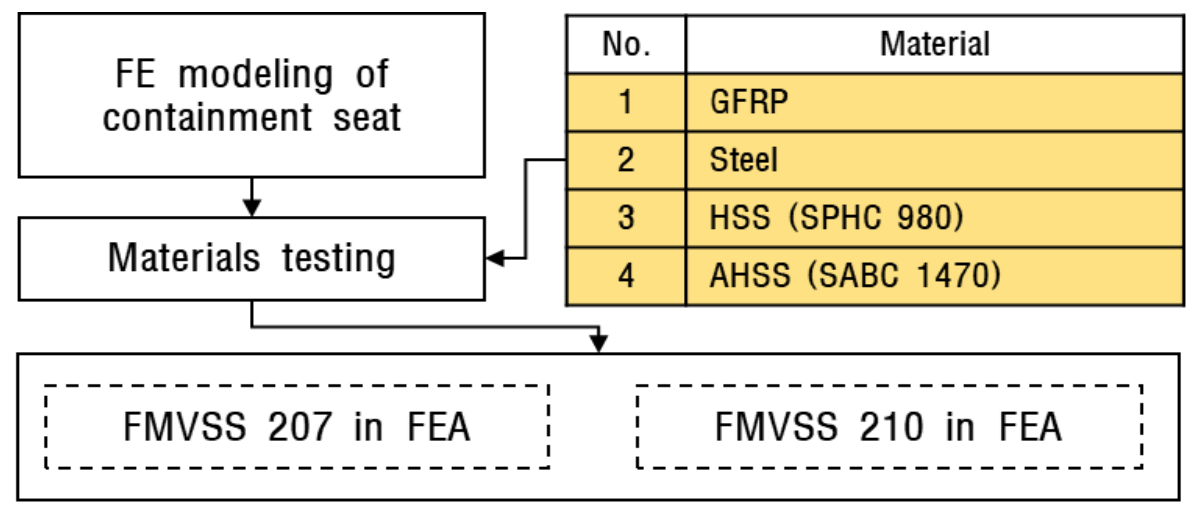

\begin{tabular}{|l|l|l|l|}
\hline \multirow{2}{*}{$\begin{array}{l}\text { Parameters } \\
\text { (DMTO) }\end{array}$} & Parameters & Properties & $\begin{array}{l}\text { Saddle } \\
\text { direction }\end{array}$ \\
\cline { 2 - 4 } & $x_{i 1}=\{1,2,3,4\} ;$ & Material number & Min. \\
\cline { 2 - 4 } & $x_{i 2}=\{0.5,1.0,1.5,2.0\} ;$ & Thickness & Min. \\
\hline Response & $M A X\left(\delta_{F M V S S} 207\right), \operatorname{MAX}\left(\delta_{F M V S S ~ 210}\right)$, Weight \\
\hline \multirow{2}{*}{ Restrict } & $\left.\begin{array}{l}M A X\left(\delta_{F M V S S} 207\right. \\
\text { MAX }\left(\delta_{F M V S S} 210\right.\end{array}\right)<$ Regulation $\left(\delta_{F M V S S ~ 207}\right)$ \\
\hline Object & \multicolumn{2}{|c|}{$\operatorname{Min}($ Weight $)$} \\
\hline Meta model & \multicolumn{2}{|c|}{ D.L.H. + Polynomial surf. + G.A. } \\
\hline
\end{tabular}

Select main parameters

\begin{tabular}{|l|c|}
\hline \multicolumn{1}{|c|}{$\cdots$} & $\cdots$ \\
\hline Object & Min (Weight) \\
\hline Meta model & D-Optimal + Polynomial surf. + G.A. \\
\hline
\end{tabular}

Analyze weight and strength

Figure 7 The procedure of discrete material and thickness optimization for light-weight seat-frame.

\subsection{Optimization using a Meta-Model}

The formulation of the optimization model for the weight reduction of the seat frame is as follows.

\section{Parameters}

\section{Minimize object function}

$$
\mathrm{x}=\left\{M_{i}, t_{i}\right\}
$$

$$
\mathrm{f}(\mathrm{M}, \mathrm{t})=\min (\text { Mass })
$$

Constraints

$$
\begin{array}{r}
\text { Displacement }(M, t)<\text { FMVSS 207 }(80 \mathrm{~mm}) \\
\text { Displacement }(M, t)<\text { FMVSS 210 }(100 \mathrm{~mm})
\end{array}
$$

Where,

$\mathrm{x}$ : Set of parameters

$M$ : Material ID applied to each part

$t$ : Thickness value applied to each part 
Figure 8(a) shows the results of the FMVSS 207 and FMVSS 210 simulation tests conducted during the optimization process. The optimization was terminated when the difference between the predicted value of the meta-model and the result of the analysis with the optimal parameters was the smallest. The FMVSS 207 and 210 standards were met in all optimization processes.

Figure 8(b) shows the changes in weight. For the DMTO, GFRP was applied to some parts. The weights of the initial model of the DMTO and the optimization model were lower than that of DTO. The results for DMTO showed that the weight could be reduced by approximately $47 \%$. Compared to the initial model of the DTO, approximately $53 \%$ weight reduction was possible in this case.

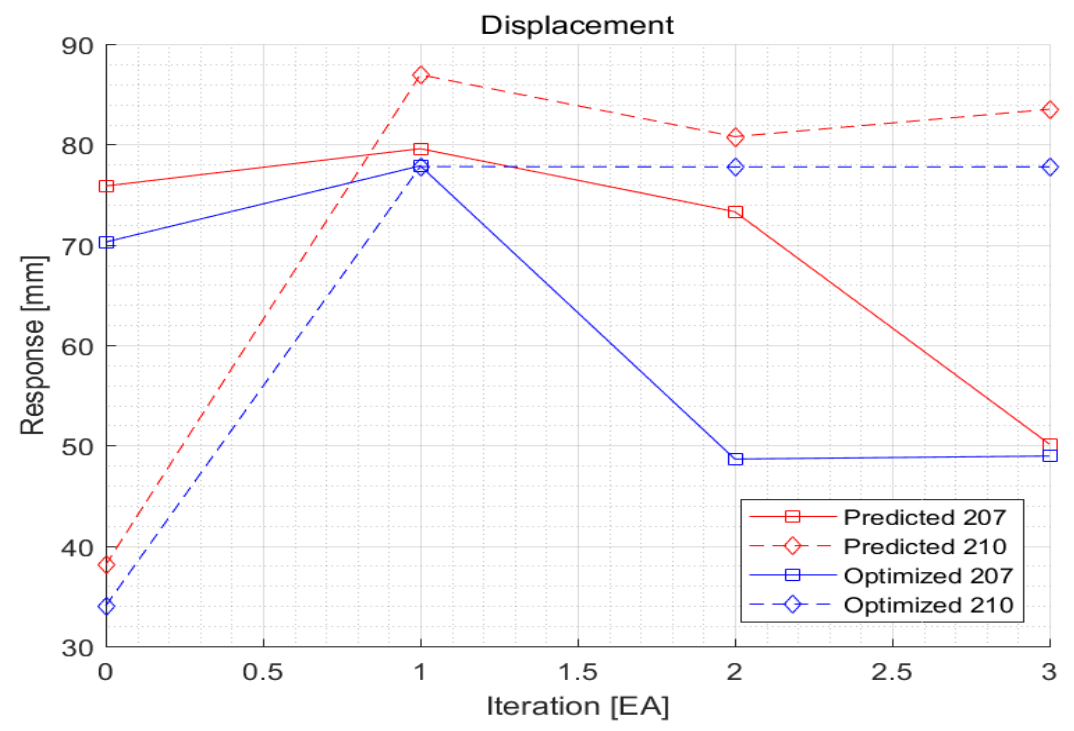

(a)

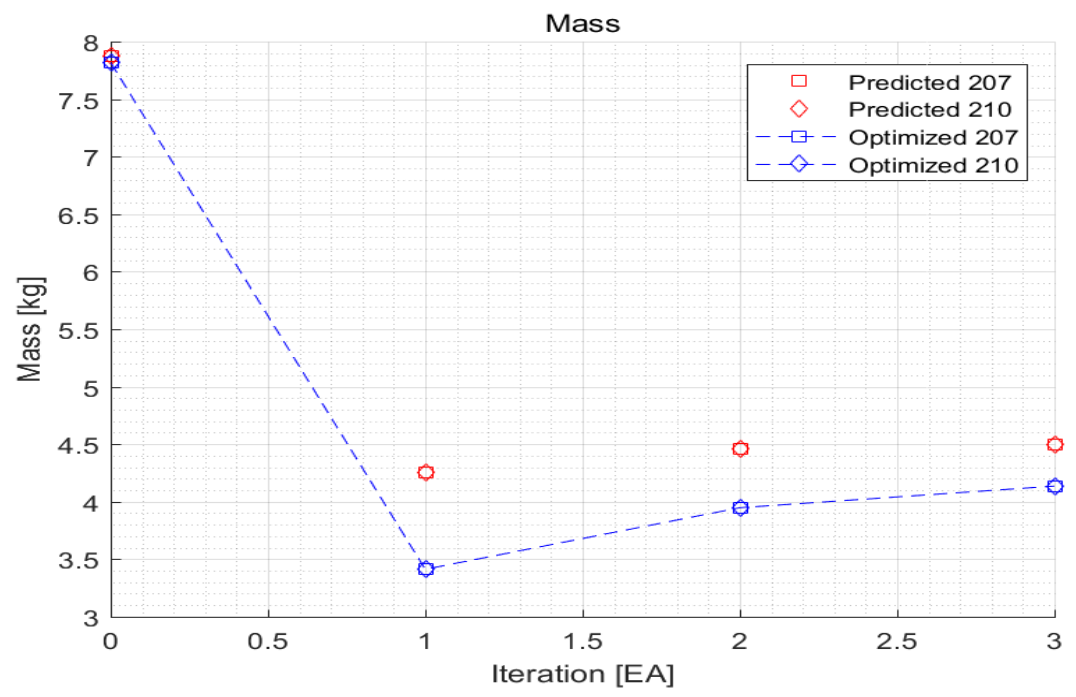

(b)

Figure 8 Result of discrete thickness optimization (a) Maximum displacement prediction of the optimization model and analysis results (b) The results of discrete thickness optimization 


\section{RESULTS \& CONCLUSION}

\subsection{Results}

In this study, the lightweight optimization of a seat frame was performed. To obtain the finite element model of the seat frame, the FMVSS 207 static test and FMVSS 210 quasi-static test environments were applied. These are standards for evaluating the strength of the model.

Thicknesses $0.5 \mathrm{t}, 1.0 \mathrm{t}, 1.5 \mathrm{t}$, and $2.0 \mathrm{t}$ were applied to each part, and material IDs GFRP 40 wt\%, Steel, SPFC 980, and SPBH 1470 were applied. The results of the finite element analysis in which the discrete parameters were applied to all parts are shown in Figure 4.

To derive the main parts of the seat frame that have a major impact on strength and weight, D-Optimal DOE and G.A. RSM were used. The main parts that significantly influence the strength and weight were selected through RSM. This process is shown in Figure 5(a). The major parameters that account for more than $4 \%$ influence on the strength and weight were selected as shown in Figures 5(b) and 5(c).

The DTO process shown in Figure 5(a) was performed for the thicknesses of the major parts. The results of performing DTO when the material was fixed at SPBH 1470 are shown in Figure 6(b). The weight reduction effect of DTO was approximately $42 \%$. Figure 6(a) shows that the optimization results met the strength standards.

The DMTO process shown in Figure 7 was performed for the materials and thicknesses of the main parts. The results of performing DMTO are shown in Figure 8(b). Approximately $47 \%$ weight reduction was possible through DMTO. Approximately 53\% weight reduction was possible compared to the initial model of DTO. Figure 8(a) shows that the optimization results met the strength standards.

\subsection{Conclusion}

The purpose of this study was the lightweight optimization of a seatback. The materials and thicknesses of the parts were considered as the design parameters for optimization. However, the parameter levels involved numerous repeated analyses. To effectively address this issue, DMTO, which is used to determine the orientation of composites, was applied. In a typical DMTO, the number of cases for all parameters is processed using algorithms, such as G.A. In this study, however, the DOE was used to reduce the number of cases, and G.A. was used for the RSM. As a result, main parts could be selected.

Through FEA, the strength was limited by the standards of static strength (FMVSS 207) and quasi-static strength (FMVSS 210). In this study, dynamic test conditions that involve failure were not considered. Therefore, ideal weight reduction effects were observed as shown in Figure 6(b) or Figure 8(b). If dynamic loads had been considered, the weight reduction effect could have been lower than in this study.

In DMTO, low-strength lightweight materials could be applied to parts with very little influence on the weight and strength. For other parts, the existing materials and thicknesses were maintained to reduce the burden of material change. For the main parts, the application of all materials and all thicknesses was considered. DMTO exhibited a better weight reduction effect than DTO. This indicates that determining materials and thicknesses according to their influence on strength and weight is a better design direction.

It is estimated that more realistic optimization results could have been derived if the strength standard had been increased considering the dynamic test or materials such as CFRP and aluminum. In future studies, more diversified test standards and materials will be used.

The results of this study are expected to be utilized more for electric vehicles, which pursue convenience and functionality more than high-strength performance. They can be 
applied in the starting phase where the materials and thicknesses of functional parts with established standard or non-standard strength standards are selected.

\section{ACKNOWLEDGMENT}

This research is supported by the Incorporated R\&D Human Resources Development Project of Small \& Medium Venture Business Department in 2019. (S2755803)

\section{REFERENCES}

[1] Aulig N, Nutwell E, Menzel S, Detwiler D., Preference-based topology optimization for vehicle concept design with concurrent static and crash load cases, Structural and Multidisciplinary Optimization, 57(1), 2018, pp. 251-266.

[2] Qin H, Guo Y, Liu Z, Liu Y, Zhong H., Shape optimization of automotive body frame using an improved genetic algorithm optimizer, Advances in Engineering Software, 121, 2018, pp. 235-249

[3] Jin D. F., Chen X. Q., A lightweight body frame conceptual design of a mini electric vehicle, Advanced Material Research, 952, 2014, pp. 223-226

[4] Vangipuram R., Failure mode characterization of AHSS in automotive seat structure assemblies, Society of Automotive Engineers, 2007, 2007-01-0791

[5] Feraboli P., Masini A., Taraborrelli L., Pivetti A., Integrated development of CFRP structures for a topless high performance vehicle. Composite Structures, 78(4), 2007, pp. 495-506

[6] Evin E., Tomáš M., Kmec J., Németh S., Katalinic B., Wessely E., The deformation properties of high strength steel sheets for auto-body components, Procedia Engineering, 69, 2014, pp. 758-767

[7] Park E. T., Kim J., Kang B. S., Song W. J., Numerical study on performance evaluation of impact beam for automotive side-door using fiber metal laminate, Composites Research, 30(2), 2017, pp. 158-163

[8] Jeong C. H., Oh H. S., Cheon S. S., Evaluation of structural strength characteristics according to cross-sectional shape of lightweight seat frame, Journal of the Korean Society of Mechanical Technology, 19(4), 2017, pp. 445-451

[9] Kong Y. S., Cho H. Y., Development of sandwich structured seat back frame using composite materials, Transactions of the Korean Society of Mechanical Engineers, A42(3), 2018, pp. 279-285

[10] Kong Y. S., Cho H. Y., Rear seat back frame design of hatch back car applying continuous fiber-reinforced thermoplastic composite material, Transactions of the Korean Society of Mechanical Engineers, A41(12), 2017, pp. 1231-1238

[11] Kim K. P., Kim S. H., Optimization of frontal crashworthiness for the weight reduction design of an auto-body member with the advanced high strength steels, Transaction of the Korean Society of Automotive Engineers, 17(2), 2009, pp. 104-111

[12] Ko D. C., An J. H., Jang M. J., Bae J. H., Kim C. H., Kim B. M., Process design of seat rail in automobile by the advanced high strength steel of DP780, Transactions of Materials Processing, 17(3), 2008, pp. 197-202

[13] Yoon W. S., Kim D. H., Kim H. S., Optimization of lightened fiber-reinforced composite city \& trekking bicycle frame, Transactions of the Korean Society of Mechanical Engineers, A40(2), 2016, pp. 147-156 
[14] Lee J. A., Hong H. T., Chun H. J., Strength design of lightweight composite bicycle frame, Transactions of the Korean Society of Mechanical Engineers, A37(2), 2013, pp. 265-270

[15] Wu C., Gao Y., Fang J., Lund E., Li Q., Discrete topology optimization of ply orientation for a carbon fiber reinforced plastic (CFRP) laminate vehicle door, Materials \& Design, 128, 2017, pp. 9-19

[16] Zhaoa T., Teng W., Hao H., Sun P., Liu Y., Simulation research on electromagnetic shielding characteristics of carbon fiber car body for railway vehicles, Procedia Computer Science, 154, 2019, pp. 537-542

[17] Han X., Hou S., Ying L., Hou W., Aliyev H., On the fracture behaviour of adhesively bonded CFRP hat-shaped thin-walled beam under axial crushing load: An experimental and modelling study, Composite Structures, 215, 2019, pp. 258-265

[18] Kadhim M. M. A., Wu Z., Cunningh L. S., Numerical study of full-scale CFRP strengthened open-section steel columns under transverse impact, Thin-Walled Structures, 140, 2019, pp. 99-113

[19] Seyfried P., Taiss E. J. M., Calijorne A. C., Li F. P., Song Q. F., Light weighting opportunities and material choice for commercial vehicle frame structures from a design point of view, Advances in Manufacturing, 3(1), 2015, pp. 19-26

[20] Sørensen S. N., Sørensen R., Lund E., DMTO - a method for discrete material and thickness optimization of laminated composite structures., Structural and Multidisciplinary Optimization, 50(1), 2014, pp. 25-47

[21] Sjølund J. H., Peeters D., Lund E., Discrete material and thickness optimization of sandwich structures, Composite Structures, 217(1), 2019, pp. 75-88

[22] Lund E., Discrete material and thickness optimization of laminated composite structures including failure criteria, Structural and Multidisciplinary Optimization, 57(6), 2018, pp. 2357-2375

[23] ASTM D638-14, Standard Test Method for Tensile Properties of Plastics, December 15, 2014

[24] ASTM E8/E8M-16a, Standard Test Methods for Tension Testing of Metallic Materials, August 1, 2016

[25] ASTM E646-16 Standard Test Method for Tensile Strain-Hardening Exponents (n Values) of Metallic Sheet Materials, February 1, 2016

[26] Zhao K., Wang L., Yan Y. C. J., Identification of post-necking stress-strain curve for sheet metals by inverse method, Mechanics of Materials, 92, 2016, pp. 107-118.

[27] Dziallach S., Bleck W., Blumbach M., Hallfeldt T., Sheet metal testing and flow curve determination under multiaxial conditions, Advanced Engineering Materials, 9(11), 2007, pp. 987-994

[28] Bournas D. A., Lontou P. V., Papanicolaou C. G., Triantafillou T. C., Textile-reinforced mortar (TRM) versus FRP confinement in reinforced concrete columns, ACI Structural Journal, 104(6), 2007, pp. 740-748

[29] Zhang Z. L., Hauge M., Ødegård J., Thaulow C., Determining material true stress-strain curve from tensile specimens with rectangular cross-section., International Journal of Solids and Structures, 36(23), 1999, pp. 3497-3516

[30] Kim J. H., Serpantié A., Barlat F., Pierron F., Lee M. G., Characterization of the postnecking strain hardening behavior using the virtual fields method, International Journal of Solids and Structures, 50, 2013, pp. 3829-3842 
[31] Joun M. S., Eom J. G., Lee M. C., A new method for acquiring true stress-strain curves over a large range of strains using a tensile test and finite element method, Mechanics of Materials, 40, 2008, pp. 586-593

[32] Kamaya M., Kawakubo M., A procedure for determining the true stress-strain curve over a large range of strains using digital image correlation and finite element analysis, Mechanics of Materials, 43, 2011, pp. 243-253

[33] Shin D. S., Jeon E. S., The design of containment mechanism for dive seat of using the 4link mechanism. The Korean Society of Automotive Engineers, 2013(11), pp. 922-923

[34] Jung H. J., Lee D. S., Kwon Y. D., Han D. H., A study of optimum design and analysis with D.O.E for automotive seat frame, The Korean Society of Automotive Engineers, 2010(11), pp. 2598-2603

[35] Shengqin L., Xinyuan F., Study of structural optimization design on a certain vehicle body-in-white based on static performance and modal analysis, Mechanical Systems and Signal Processing, 135, 2020, pp. 106405

[36] Lee H. Y., Lim J. Y., Bom H. T., The finite element analysis of car seat frame according to the FMVSS strength test, Transaction of the Korean Society of Automotive Engineers, 7(6), 1999, pp. 241-247

[37] Kim H. Y., Lee S. K., Prediction of impact characteristics for automobile seat, Transaction of the Korean Society of Automotive Engineers, 7(3), 1999, pp. 196-204

[38] Salim M., Sanjay Y., Shinde D., Deshpande G., Importance of federal motor vehicle safety standards 207/210 in occupant safety - A case study, Procedia Engineering, 64, 2013, pp. 1099-1108

[39] Durbin D. R., Jermakian J. S., Kallan M. J., McCartt A. T., Arbogast K. B., Rear seat safety: Variation in protection by occupant, crash and vehicle characteristics, Accident Analysis \& Prevention, 80, 2015, pp. 185-192

[40] Jang G. W., Yoon M. S., Park J. H., Lightweight flatbed trailer design by using topology and thickness optimization, Structural and Multidisciplinary Optimization, 16(5), 2010, pp. 791-797

[41] Doh J. H., Lee J. S., Approximate multi-objective optimization of a wall-mounted monitor bracket arm considering strength design conditions, Transactions of the Korean Society of Mechanical Engineers, A39(5), 2015, pp. 535-541 